\title{
Analysis of Obstetric Near Miss Cases of Different Health Facilities of Electoral Constituency Two of Arghakhanchi District
}

Manandhar SR 1 , Manandhar DS ${ }^{2}$, Adhikari D², Shrestha $\mathrm{JR}^{2}$, Rai C $\mathrm{C}^{3}$, Rana $\mathbf{H}^{3}$, Paudel $\mathbf{M}^{3}$

${ }^{1}$ Department of Pediatrics, Kathmandu Medical College Teaching Hospital, ${ }^{2}$ Mother and Infant Research Activities (MIRA), ${ }^{3}$ Health Right International (HRI), Kathmandu, Nepal

Received: March 20, 2014; Accepted: December 2, 2014

\begin{abstract}
Aims: This study was done to identify and analyze obstetric near miss cases at health facilities of electoral constituency number 2 (EC 2) of Arghakhanchi district, Nepal.

Methods: After receiving one day training on identifying obstetric near miss cases, health facility staff of EC 2 of Arghakhanchi district filled up WHO derived obstetric near miss forms for eight months duration. Causes of obstetric near miss cases were identified and analyzed in SPSS 16.
\end{abstract}

Results: There were 31 obstetric near miss cases reported from different health facilities of EC 2 of Arghakhanchi. The commonest cause of obstetric near miss was Post-partum Hemorrhage $(85 \%, n=26)$ followed by obstructed labor and ante partum hemorrhage $(6 \%$, $n=2)$ each. The leading cause of PPH was retained placenta/placental tissue in $55 \%$ cases (14) followed by atonic uterus $(27 \%$, $n=7)$. Two fifth of the mothers $(39 \%, \mathrm{n}=12)$ developed complication during labor. The most common complication developed after labor was hemorrhage.

Conclusions: This study highlighted PPH as the most common serious obstetric problem in the health facilities and indicates the need for provision of blood transfusion at the health facility at least at Arghakhanchi.

Keywords: hemorrhage; obstetric near miss; PPH.

\section{INTRODUCTION}

Obstetric near miss is a newly recognized tool for investigating serious maternal morbidity. Currently, in developing countries maternal death is in declining phase and there has been marked reduction in maternal mortality ratio (MMR) even in Nepal. Recently in Nepal, maternal mortality ratio has decreased from 539 per 100,000 live birth in 1998 to 229 per 100,000 live birth in $2008-2009 .{ }^{1}$ World Health Organization (WHO) has introduced a tool to recognize obstetric near miss cases to identify women at higher risk of maternal death and thus further reduction in maternal morbidity and mortality in developing countries. This is a part of operational research (OR) programme conducted by Mother and Infant Research Activities (MIRA) and Health

\section{CORRESPONDENCE}

Dr Sunil Raja Manandhar

Department of Pediatrics, Kathmandu Medical College Teaching

Hospital, Kathmandu, Nepal.

Email: drsunilraja@gmail.com

Phone: +977-9803812218
Right International (HRI) on strengthening the health facilities of electoral constituency No. 2 (EC 2) of Arghakhanchi district, Nepal. Most of the parts of Arghakhanchi district is in the hills, with an area of 1,193 square kilometers. Available statistics from 2001 fail to disaggregate population sub-groups adequately, but the main groups defined are Magar, Brahman, Chhetri, Dalit, Newar and Kumal. ${ }^{2}$ The per capita income in Arghakhanchi district is \$207, compared to the national average of $\$ 240 .^{2}$

Obstetric near miss is defined as a condition when a woman who nearly dies due to a complication that occurred during pregnancy, childbirth or within 42 days of termination of pregnancy survives with appropriate treatment. ${ }^{3}$ Near-miss events are also defined as acute obstetric complications that immediately threatens a woman's survival but do not result in her death either by chance or because of hospital care she receives during pregnancy, labor within 6 weeks after termination of pregnancy or delivery. ${ }^{4}$ So, objective of this study was to identify 
and analyze obstetric near miss cases at health facilities of EC 2 of Arghakhanchi district, Nepal.

\section{METHODS}

One part of operational research program conducted from $1^{\text {st }}$ Oct $2010-14^{\text {th }}$ April 2013 was to train the health facility staff for identifying and recording obstetric near miss cases. So, one day training on identifying obstetric near miss case was given by senior doctors at Arghakhanchi district hospital to the health staff of health facilities of EC 2 of Arghakhanchi district on the 26th and 27th of July 2012, for two groups respectively. Thirty seven health personnel including doctors, staff nurses, Health Assistants (HAs) and Auxiliary Nurse Midwives (ANMs) from six health facilities of EC 2 of Arghakhanchi district have participated in this training for completing the WHO Obstetric near miss case form. ${ }^{5}$ Obstetric near miss cases were identified and documented on WHO obstetric near miss form for eight months period from August 2012 to March 2013.

The health facilities included in this study are Arghakhanchi District Hospital, Thada PHCC (Primary Health Care Centre), Pokharathok HP (Health Post), Siddhara HP, Subarnakhal HP and Narpani HP. Ethical approval for this operational research was taken by Ethical Review Board of Nepal Health Research Council (NHRC). Data were analyzed in frequency and tabulation in SPSS version 16. Obstetric near miss cases were identified and its causes were analyzed. On cross tabulation among home delivery and health facility delivery, $x^{2}$ test was applied and $p$ value $<0.05$ was taken as significance.

\section{RESULTS}

A total of 31 obstetric near miss cases were reported from six health facilities of EC 2 of Arghakhanchi district. Among them, 16 cases were from Arghakhanchi district hospital, four cases from Subarnakhal HP (Healthpost), eight cases from Thada PHC (Primary health centre), two cases from Pokharathok HP and one case from Siddhara HP. During identification of causes of obstetric near miss cases, the commonest cause was PPH in $85 \%$ (26) followed by obstructed labor and antepartum hemorrhage at $6 \%(2)$, each (Figure 1). The leading cause of PPH was retained placenta / placental tissue in $55 \%$ (14) cases followed by atonic uterus $27 \%$ (7), cervical tear $15 \%$ (4) and 2nd degree perineal tear 3\% (1) (Figure 2).
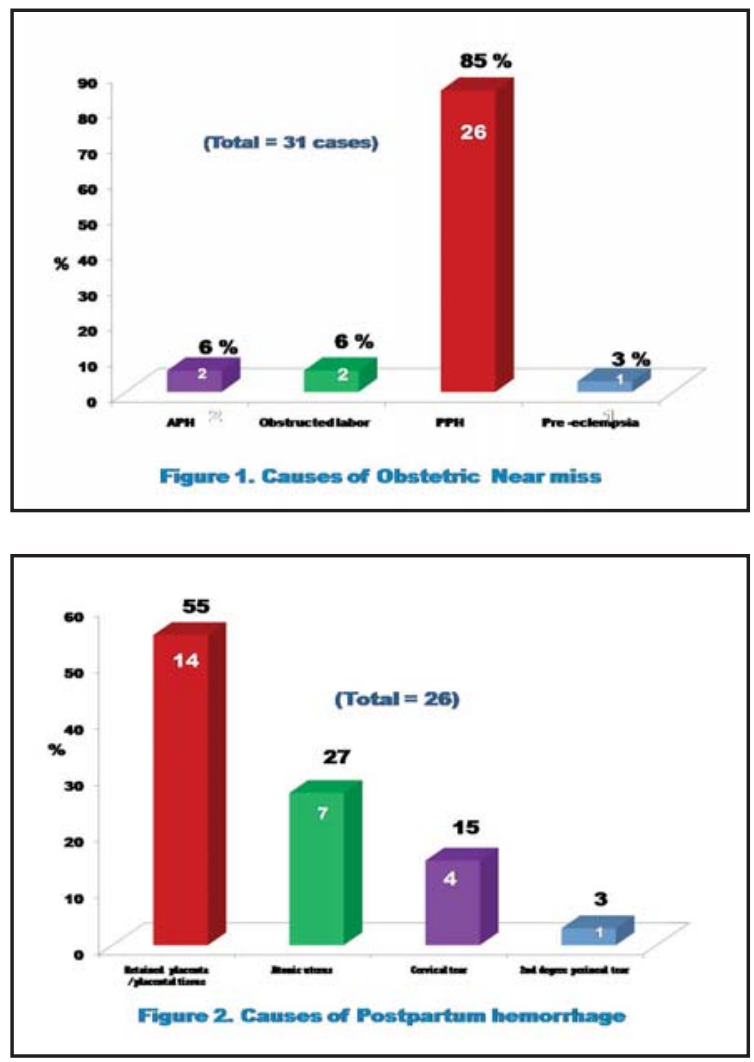

Table 1 describes the characteristics of women included in the study. Out of 31 women, $25 \%$ (8) were of less than 20 years of age. Most of the mothers were primigravida $(65 \%, \mathrm{n}=20)$. Similarly, Table 2 describes $77 \%$ (24) mothers were delivered at health facilities followed by home delivery $16 \%$ (5 cases) and 39\% (12) mothers developed complication during labor. The most common complication 87\% (27) after labor was Post Partum Hemorrhage (PPH).

\begin{tabular}{|lc|}
\hline Table 1. Maternal characteristics $(\mathrm{n}=32)$ \\
\hline Mothers Age & Number $\%$ \\
$<20$ years & $8(25)$ \\
$\geq 20$ years & $17(55)$ \\
Don't know age & $6(20)$ \\
Primipara & $20(65)$ \\
Multipara & $6(20)$ \\
Parity not mentioned & $5(15)$ \\
\hline
\end{tabular}




\begin{tabular}{|lc|}
\hline $\begin{array}{l}\text { Table 2. Place of delivery, problems, and complications } \\
\text { encountered during }\end{array}$ & and \\
after labor $(\mathrm{n}=32)$
\end{tabular}

Figure 3 describes the relation of labor complications with respect to place of delivery. There were total of 24 deliveries at health facilities, among them $62 \%$ (15) pregnant women developed labor complications, whereas among 5 home deliveries, $100 \%$ (all 5 cases) developed complications, which is statistically significant ( $p$ 0.001).

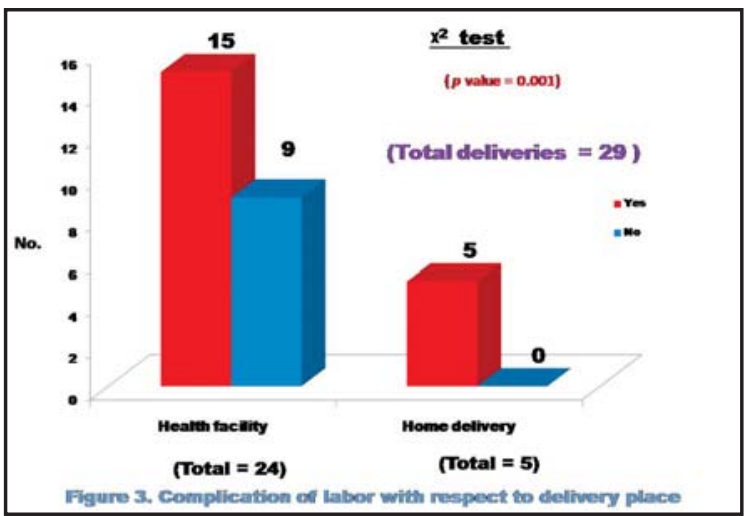

While analyzing interventions done to manage those 31 cases of obstetric near miss, 48\% (15) were managed by exploration with removal of retained placenta, 24\% (7) were managed with manual removal of placenta (MRP) and cervical tear repair was done in 13\% (4). Similarly D and C (dilation and curettage) was done in $6 \%$ (2) cases and one case (3\%) was managed with pre-eclempsia whereas two cases $(6 \%)$ were referred to Lumbini Zonal hospital after initial supportive treatment done at Arghakhanchi district hospital, which are depicted in Figure 4.

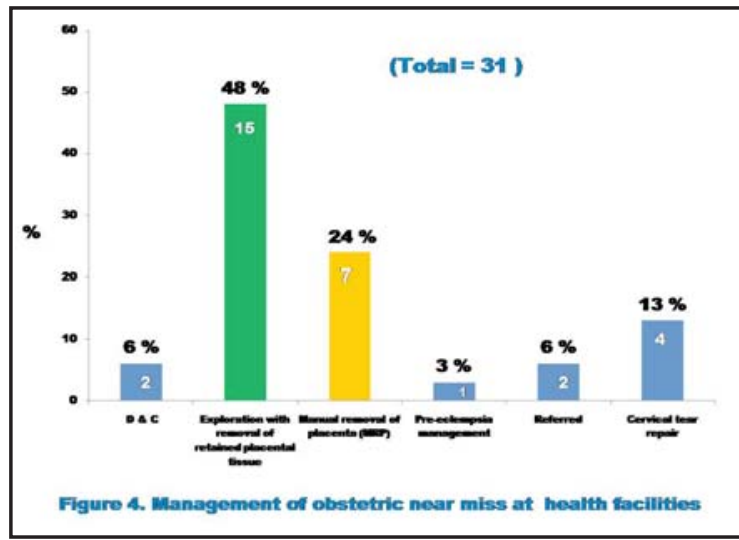

\section{DISCUSSION}

Hemorrhage was the most common cause of obstetric complication, with PPH being commonest. Most of the patients received appropriate management at health facilities and thus became well. Those women would have died if they had not received appropriate care at health facilities of EC 2 of Arghakhanchi district. A study done at Kathmandu Medical College Teaching Hospital (KMCTH) by Shrestha NS found hemorrhage $(41.66 \%)$ as the commonest cause of obstetric near miss followed by hypertensive disorder of the pregnancy $(27.77 \%)$ and PPH contributed $20 \%$ among hemorrhage. ${ }^{6}$ Similarly, a study done at Kasturba Hospital, Karnataka, India by Sarun Sarun et $\mathrm{al}^{7}$ found hemorrhage was the leading cause (44.2\%) followed by hypertension (23.6\%) among the obstetric near miss cases. In 2012, a big multicentric study done in Nepal by Rana et $\mathrm{al}^{8}$ also highlighted PPH $(40 \%, n=62)$ as a commonest cause of maternal near miss followed by hypertensive disorders of pregnancy $(17 \%, n=25)$.

\section{CONCLUSIONS}

This study also highlighted PPH being the most common serious obstetric complication in the health facilities. Recording and discussion of such obstetric near miss cases can increase awareness among health staff and helps to improve management of similar cases in future. 


\section{ACKNOWLEDGEMENT}

We would like to acknowledge Dr Yam Bahadur Basnet, DHO Arghakhanchi district, Mr. Lila Ram Gautam, DPHO, medical officers, nurses and paramedical staff of the Arghakhanchi District Hospital, Thada PHC, Narpani HP, Pokharathok HP, Subarnakhal HP and Siddhara HP, and Dr. Kasturi Malla for their support and cooperation during this operational research program.

\section{DISCLOSURE}

The authors report no conflicts of interest in this work.

No violation of human rights and safety.

Funding: This study was done with a technical support from Mother and Infant Research Activities (MIRA) and funded by Health Right International (HRI) with support from USAID (United States Agency for International Development).

\section{REFERENCES}

1. Nepal maternal mortality and morbidity study 2008/09. Summary of preliminary findings, Nepal. Kathmandu: Family Health Division, Department of Health Services, Government of Nepal; 2010

2. Sharma NK. Arghakhanchi. In: Joshi SR, Bhandari H, editors. District Profile of Nepal 2007/ 08. Kathmandu: Intensive Study and Research Centre; 2007. p. 583-94

3. Say L, Souza JP, Pattinson RC. Maternal near miss - towards a standard tool for monitoring quality of maternal health care. $2009 ; 23(3): 287-96$

4. Ronsmans C, Filippi V. Reviewing severe maternal morbidity: learning from survivors from life-threatening complications. In beyond the numbers: reviewing deaths and complications to make pregnancy safer. Geneva: World Health Organization; 2004:103-24
5. World Health Organization. Evaluating the quality of care for severe pregnancy complications: the WHO near-miss approach for maternal health 2011, scientific report series 21 .

6. Shrestha NS, Saha R, Karki C. Near miss maternal morbidity and maternal mortality at Kathmandu Medical College Teaching Hospital. KUMJ. 2010;8(30):222-6.

7. Sarun RP, Verma S, Rai L, Kumar P, Pai MV, Shetty J. "Near miss" obstetric events and maternal deaths in a tertiary care hospital: an audit. Journal of Pregnancy. 2004;1(1):10-19.

8. Rana A, Baral GN, Dangal G. Maternal near-miss: a multicenter surveillance in Kathmandu valley. J Nepal Med Assoc. 2013;52(190):299-304. 